\title{
Investigation of antioxidant and antimicrobial activities of Euclea schimperi leaf extracts
}

\author{
Alemayehu Mekonnen ", Minaleshewa Atlabachew and Banchalem Kassie
}

\begin{abstract}
Background: Bioactive components from medicinal plants are said to be responsible for the antioxidant and antimicrobial effects of plant extracts. It was the main purpose of this paper to evaluate the total phenolic content (TPC), total flavonoid content (TFC), and antioxidant and antimicrobial activities of leaf extracts of Euclea schimperi.

Results: Strong evidence was found when a positive correlation was found between TPC or TFC and antioxidant power. To put it differently, TPC of the E. schimperi leaf extracts varied between $748.78 \pm 3.11 \mathrm{mgGAE} / 100 \mathrm{~g}$ of dry extract (methanol) and $40.45 \pm 0.66 \mathrm{mgGAE} / 100 \mathrm{~g}$ of dry extract (chloroform) while TFC varied from $3.306 \pm 0.142 \mathrm{mgQE} / 100 \mathrm{~g}$ of dry extract (methanol) to $0.334 \pm 0.002 \mathrm{mgQE} / 100 \mathrm{~g}$ dry extract (chloroform). Similarly, all extracts exhibited significant amount of antioxidant and antimicrobial activities. Ferric reducing power was ranged between $312.145 \pm 1.542 \mathrm{mgAAE} / 100 \mathrm{~g}$ extract (methanol) and $48.177 \pm 0.286 \mathrm{mgAAE} / 100 \mathrm{~g}$ (chloroform). DPPH radical scavenging activity (\%) lied between $83.4 \%$ (methanol) and $58.5 \%$ (chloroform). The voltammetric analysis of the crude extract gave three different sharp peaks at the oxidation potential side. Finally, the reducing agent capacity of the extracts was further confirmed by synthesizing silver nanoparticles from $\mathrm{AgNO}_{3}$ solution and the plant crude extracts. Crude extracts of E. schimperi leaves showed various degree of antimicrobial activity towards different standard strains with mean zone of inhibition ranging from 0 to $20.67 \mathrm{~mm}$. Both solvent leaf extracts of $E$. schimperi exhibited MIC ranging from 62.5 to $125 \mathrm{mg} / \mathrm{mL}$ towards most bacterial species.

Conclusions: Euclea schimperi leaf extracts were found to contain high amount of total phenolic and small amount of flavonoid compounds which play a major role in controlling oxidation. In general, therefore, the results prove the effectiveness of the plant for its excellent antioxidant and antimicrobial activities. Accordingly, the positive values of the plant in traditional medicines have been confirmed.
\end{abstract}

Keywords: Euclea schimperi, Free radicals, Antioxidants, Total phenolic content, Total flavonoid content, Antibacterial activity, Minimum inhibitory concentration

\section{Introduction}

Traditional medicine is regarded as a combination of knowledge, skill and practice originated from theories, experiences and attitudes native to various cultures that is utilized to treat and diagnose enormous types of physical and mental complications and maintain health [1]. Many people in the world rely on traditional medicine

*Correspondence: negaalex@yahoo.com; alemayehum@bdu.edu.et Chemistry Department, Science College, Bahir Dar University, P.O. Box: 79, Bahir Dar, Ethiopia for their primarily health care needs. It is well understood that several medical techniques and procedures have been discovered from the use and knowledge of traditional medicines. This is because the major part of traditional therapy involves the use of plant extracts or their active principles. As a result, natural products have recently become of immense interest owing to their diverse application [2].

Since in the early stage, plants have been used as a source of medicinal compounds and still continued to play a major role in the human health [3]. They are the 
source of drugs in the traditional and modern medicine, nutraceuticals, food supplements, folk medicines and precursors for synthetic drugs [4]. The discoveries of potential new drugs have been led by screening bioactive compounds from plants having efficient activity against various diseases [5].

Phytochemicals are bioactive and naturally occurring compounds originating in plants, which act against pathogens and provide health benefits for humans [6]. Among the prevalent group of phytochemicals, alkaloids, terpenes, flavonoids and phenolic compounds are widely found in most plants and plant parts [7]. Extracts of plant parts (fruits, seeds, leaves, etc.) are used for medicinal effects, among which some of the classes of compounds have antioxidant activity against reactive species in the body [8].

The most recognized antioxidants derived from medicinal plants are phenolic compounds and have high antioxidant activity against free radicals. However, the extent of the activity depends on the structure of the molecules $[8,9]$. These antioxidant constituents are closely associated to the prevention of degenerative diseases, such as cardiovascular and neurological illnesses, oxidative stress malfunctions and cancer $[9,10]$.

Euclea schimperi, from the family of Ebenaceae, is traditionally used in the treatment of wound, teeth infections, eye disorders, headache, pain and spasm. In Ethiopia, the leaf of this plant is used to treat illness such as gonorrhea, eczema and constipation. In addition, they treat the pots in which milk is kept with the smoke of $E$. schimperi branches to prevent the milk from curdling $[11,12]$. The leaves is also used for the treatment of skin disorders, snake biting, scabies, leprosy, Tinea capitis, acne, warts, rheumatic pain and elephantiasis [13].

Despite the wide therapeutic potential presented by $E$. schimperi leaves in Ethiopia, studies on the phytochemical profile, antioxidant and antimicrobial activities of the leaves of this plant are still lacking. Only one other MSc thesis abstract posted on Khartoum University website, to our knowledge, has come up with the antioxidant and antibacterial activity of Sudanese E. schimperi leaf extract (http://khartoumspace.uofk.edu/handle/12345 6789/16116). Consequently, in our study, the focus of attention was on the determination of the content of some selected phytochemicals, evaluation of antioxidant and antimicrobial activities of the leaf extracts of Ethiopian E. schimperi.

\section{Experimental section}

\section{Sample collection}

The leaves of E. schimperi were collected from Bahir Dar University main campus. The plant was identified by its local name "Dedeho" (Amharic) and registered in Ethiopian folk medicine. A herbarium voucher (Banchalem-001) was identified by Dr. Ali Seid and deposited in the mini-herbarium of a Bahir Dar University (Bahir Dar, Ethiopia). The leaves of the plant were detached from the parent plant and were washed with tape water and placed in shade at room temperature without exposing to sun light and heat for 2 weeks. The air-dried leaves of E. schimperi were chopped into small pieces and milled into a uniform powder with a coffee grinder. The powder was packed in polyethylene bags and stored in refrigerator for further use.

\section{Extraction procedure}

The powdered leaf of E. schimperi was extracted by two different solvents (methanol and chloroform). In each extraction process, $60 \mathrm{~g}$ of dry powder was socked in $600 \mathrm{~mL}$ of each solvent with ratio of 1:10 (W/V) of the plant material to solvents as per standard method for extraction of medicinal plant [14]. The mixtures were extracted up on shaking with mechanical shaker for $48 \mathrm{~h}$. Then, the extracts were filtered and concentrated using a rotary evaporator under reduced pressure at a maximum of $25{ }^{\circ} \mathrm{C}$. Crude extracts obtained using methanol and chloroform solvents were labeled as $E S L_{1}$, and $E S L_{2}$, respectively. The yields were calculated and preserved using air tight bottles at $4{ }^{\circ} \mathrm{C}$ refrigerator. In all cases, the extracts were tested in triplicates and the mean values were tabulated.

\section{Statistical analysis}

Data were presented as mean \pm SD from triplicate measurements and significance differences between groups were determined by one-way ANOVA followed by Tukey post hoc test and paired $t$ test. Differences were considered significant when $p<0.05$.

\section{Experimental procedures \\ Preliminary phytochemical screening}

The leaves of E. schimperi were subjected to preliminary phytochemical tests following standard procedures described for the screening of phytochemical constituents (alkaloids, polyphenols, flavonoids, saponins, tannins, glycosides, and terpenoids). Methanol and chloroform extracts were screened for the presence of steroids, terpenoids, flavonoids, phenolics, tannins and saponins following standard method [15]. All tests were performed in triplicates.

\section{Determination of total polyphenols}

Total phenolic content of E. schimperi leaf extracts was determined according to the Folin-Ciocalteu method with slight modification [16]. Gallic acid was used as reference compound for positive control. Exactly $5 \mathrm{~mL}$ 
of plant crude extracts (methanol and chloroform) was diluted with $45 \mathrm{~mL}$ of distilled water. Folin-Ciocalteu reagent $(0.25 \mathrm{~mL})$ was added to $5 \mathrm{~mL}$ of the diluted extract solution followed by $0.5 \mathrm{~mL}$ of $7 \%$ sodium carbonate $\left(\mathrm{Na}_{2} \mathrm{CO}_{3}\right)$ solution. The contents were mixed and the flask made up to volume with distilled water then thoroughly mixed. The mixtures were left for $30 \mathrm{~min}$ in the dark and the absorbance was measured at $750 \mathrm{~nm}$.

\section{Determination of total flavonoids}

The total flavonoid content of E. schimperi leaf methanol and chloroform extracts was determined by aluminum chloride assay with slight modifications [17]. Quercetin was used as standard compound. A sample extract of $2.00 \mathrm{~mL}$ was mixed with $4.00 \mathrm{~mL}$ of distilled water, followed by an immediate addition of $0.30 \mathrm{~mL}$ of $5 \% \mathrm{NaNO}_{2}$. After $5 \mathrm{~min}, 0.30 \mathrm{~mL}$ of $10 \% \mathrm{AlCl}_{3}$ solution was added. After $6 \mathrm{~min}, 2.00 \mathrm{~mL}$ of $1.00 \mathrm{M} \mathrm{NaOH}$ solution was added and then $10 \mathrm{~min}$ later, absorbance of the resulting solution was taken at $510 \mathrm{~nm}$.

\section{Measure of antioxidant activities a. Reducing power assay}

The reducing power of the extract was determined according to the method reported by Mitic et al. [18] with slight modification. Ascorbic acid was used as reference. Different concentrations (10, 20, 30, 40\%, v/v) of $5.00 \mathrm{mg} / \mathrm{mL}$ of stock solutions of E. schimperi leaf extracts were prepared for each solvent (methanol, and chloroform). From each solution, $2.50 \mathrm{~mL}$ was taken and mixed with $2.5 \mathrm{~mL}$ of $0.20 \mathrm{M}$ sodium phosphate buffer (pH6.6) and $2.5 \mathrm{~mL}$ of potassium ferricyanide solution (1\%). The mixtures were incubated in water bath at $50{ }^{\circ} \mathrm{C}$ for $20 \mathrm{~min}$ then, $2.5 \mathrm{~mL}$ of trichloroacetic acid (TCA) solution $(10 \% \mathrm{w} / \mathrm{v})$ was added and the resulting mixture was centrifuged at $3000 \mathrm{rpm}$ for $10 \mathrm{~min}$. The supernatant (2.5 mL) was taken, mixed with $2.5 \mathrm{~mL}$ of distilled water and $0.5 \mathrm{~mL}$ of a ferric chloride solution $(0.1 \% \mathrm{w} / \mathrm{v})$ and the absorbance of the resulting solution was measured at $700 \mathrm{~nm}$.

\section{b. DPPH radical scavenging activity determination}

The antioxidant activity of E. schimperi leaf extracts was also assessed on the basis of the free radical scavenging effect of DPPH (2, 2-diphenyl-1-picrylhydrazyl) using the method described by [19]. Ascorbic acid was used as positive control. The methanol and chloroform extracts from E. schimperi leaves with different concentrations [40, 30, 20, 10\% (v/v)] of $5.0 \mathrm{mg} / \mathrm{mL}$ stock solutions were prepared. $5.0 \mathrm{~mL}$ of $0.004 \%$ of DPPH solution was mixed with $1 \mathrm{~mL}$ of each extract solution. The solutions were kept in the dark for $30 \mathrm{~min}$ to complete the reaction and then the absorbance of the mixture was measured at $517 \mathrm{~nm}$.

\section{c. Voltammetric analysis}

The $80 \mathrm{mg} / \mathrm{mL}$ concentration of leaf extracts of methanol from E. schimperi leaves was subjected to voltammetric analysis to measure antioxidant capacity of the sample. It has to be noted that methanol and chloroform extracts were found to contain high and low amount of antioxidants, respectively. Thus, only methanol extract was considered for further comparative analysis using voltammetric method. Exactly $15.00 \mathrm{~mL}$ of each sample extract was diluted to $50.00 \mathrm{~mL}$ with acetate buffer solution $(0.10 \mathrm{M})$ of $\mathrm{pH} 5$. Then, cyclic voltammogram of each sample was obtained by scanning the potential from -1000 to $1400 \mathrm{mV}$ at a scan rate of $100 \mathrm{~m} \mathrm{Vs}^{-1}$. Acetate buffer was used as a blank.

All the voltammetric measurements were carried out in a $25-\mathrm{mL}$ cell at room temperature, in a three-electrode configuration. Graphite carbon electrode was used as a working electrode. The reference electrode was an $\mathrm{Ag} \mid \mathrm{AgCl}$ salt and the counter electrode was a platinum wire. Cyclic voltammetric measurements were performed in model 700E series electrochemical analyzer connected to a desktop computer. For further relaxation of the peak, the sample was scanned with square wave voltammetry.

\section{d. Synthesis of silver nanoparticles}

Antioxidant capacity of E. schimperi was measured in terms of reduction ability of silver to synthesize silver nanoparticles (AgNPs) based on the method described by Shankar et al. [20] with slight modification. Two different solvent extracts (methanol and chloroform) were prepared with the same concentration. Methanol extract was prepared with different concentrations (10, 20, $30,40 \% \mathrm{v} / \mathrm{v}$ ) of $5 \mathrm{mg} / \mathrm{mL}$ stock solution to measure the reduction potential. $10 \mathrm{~mL}$ of $5 \mathrm{mM}$ silver nitrate solution was mixed with $1 \mathrm{~mL}$ of each sample in the dark by stirring magnetically for $15 \mathrm{~min}$.

The reduction of metallic silver ions was monitored by measuring the absorbance after different time for different concentration of the reaction. The absorbance of the mixture was scanned between 300 and $600 \mathrm{~nm}$ using $\mathrm{UV}-\mathrm{Vis}$ spectrometer after 2, 6, 9 and $24 \mathrm{~h}$ of the reaction begins.

\section{Antibacterial activity determination Disk diffusion method}

The present study was conducted using standard disk diffusion method [21]. Different extract (methanol and chloroform) of E. schimperi leaves were used by agar disk diffusion method on Mueller-Hinton Agar (MHA) medium to measure the antimicrobial activity. Standard 
Table 1 Result of phytochemical screening of different solvent extracts of Euclea schimperi leaves

\begin{tabular}{lllll}
\hline Phytochemicals & \multicolumn{2}{l}{ Types of extracts } & & Color observed \\
\cline { 2 - 3 } & Methanol & Chloroform & & Reagents/methods used \\
\hline Saponins & +++ & + & Stable froth & Froth test \\
Tannins & +++ & - & Yellow ppt & Lead acetate test \\
Phenolics & +++ & + & Blue black color & Ferric chloride test \\
Flavonoids & ++ & - & Yellow ppt & Lead acetate test \\
Terpenoids & ++ & - & Reddish brown ring & $\mathrm{CHCl}_{3}+\mathrm{H}_{2} \mathrm{SO}_{4}$ \\
Steroids & +++ & - & Reddish brown color & Sulfuric acid test \\
\hline
\end{tabular}

+++ : present in highest concentration, ++ : present in high concentration, + : present in moderate concentration, $-:$ absent $[15,22,23]$

Table 2 Total phenolic content (TPC) expressed as mg GAE/100 g dry extract and total flavonoids content expressed as $\mathrm{mg} \mathrm{QE} / 100 \mathrm{~g}$ dry extract of different solvent extracts of Euclea schimperi leaves

\begin{tabular}{|c|c|c|c|c|}
\hline Type of extract & $\begin{array}{l}\text { Total phenolics in mg } \\
\text { GAE/100 g dry ext. }\end{array}$ & $\begin{array}{l}\text { Total flavonoids mg } \\
\text { QE/100 g dry ext. }\end{array}$ & $\begin{array}{l}\text { Antioxidant activity a FRAP (mg } \\
\text { AAE/100 g dry extract) }\end{array}$ & $\begin{array}{l}\text { Antioxidant activity } \\
\text { a DPPH (mgAAE/100 g } \\
\text { dry ext. }\end{array}$ \\
\hline Methanol extract & $748.78 \pm 3.11^{a}$ & $3.306 \pm 0.142^{a}$ & $312.145 \pm 1.542^{a}$ & $19.707 \pm 0.186^{a}$ \\
\hline Chloroform extract & $40.45 \pm 0.66^{b}$ & $0.334 \pm 0.002^{b}$ & $48.177 \pm 0.286^{b}$ & $2.717 \pm 0.030^{b}$ \\
\hline
\end{tabular}

Sample for three independent measurements (triplicate; $n=3$, mean \pm SD). Values in the same column that are followed by a different letters (a, b) are significantly different $p<0.05$ by paired $t$ test

size Whatman No. 1 filter paper disks, $5.0 \mathrm{~mm}$ in diameter, sterilized by moist heat at $121 \mathrm{lb}$ in an autoclave for 15 min was used to determine antibacterial activity.

MHA medium for $S$. aureus, $p$. aeruginosa, K. pneumoniae, and S. pneumoniae was prepared for disk diffusion test. After sterilization, it was poured into sterilized Petri dish plates and allowed to solidify. Then, 1-day-old fresh culture of bacteria was used for inoculum preparation. A suspension that will be just turbid ( 0.5 McFarland standard) by visual inspection was prepared by suspending bacteria in $0.9 \% \mathrm{NaCl}$ solution and the homogeneous suspension was used for inoculation. Using a sterile cotton swab, bacterial cultures were swabbed on the surface of sterile agar plates. Sterile 5-mm disks was impregnated with $50 \mu \mathrm{L}$ of extract and placed on the surface of agar plates inoculated with a microbial culture. After overnight incubation, the plates were observed for the zone of inhibition and the diameter of the inhibition zone was measured in millimeter.

Standard antibiotics, erythromycin, chloramphenicol, gentamycin and ciprofloxacin $(10 \mu \mathrm{g} / \mathrm{mL})$ served as positive control and sterile distilled water and chloroform used to dilute plant extract were used as negative control.

\section{Determination of minimum inhibitory concentration}

The broth dilution technique [22] was employed to determine the MIC of the potent extracts. Standardized inoculums of the test organisms was inoculated into series of

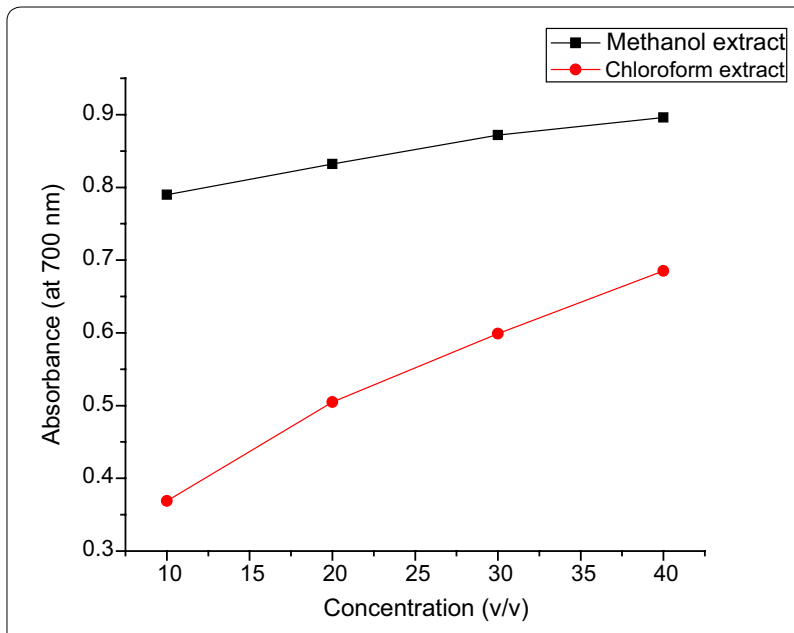

Fig. 1 Reducing power of Euclea schimperi leave extracts, expressed as absorbance at $700 \mathrm{~nm}$. Different concentrations (10, 20, 30, 40\%, $\mathrm{v} / \mathrm{v}$ ) of $5.00 \mathrm{mg} / \mathrm{mL}$ of stock solutions of Euclea schimperi leaf extracts were prepared for each solvent (methanol, and chloroform). The graph shows that the reducing power increases with increasing concentration. The antioxidant capacity of methanol extract was significantly higher than that of the chloroform extract

sterile tubes of $2 \mathrm{~mL}$ nutrient broth containing 500, 250, $125,62.5$ and $31.25 \mathrm{mg} / \mathrm{mL}$ of each extracts and incubated at $37{ }^{\circ} \mathrm{C}$ for $24 \mathrm{~h}$. The lowest concentration of the extract that produced indication of growth (Turbidity) was recorded as the MIC. 


\section{Results and discussion}

\section{Phytochemical screening tests}

The preliminary phytochemical tests are helpful in finding information about chemical constituents present in the plant material [22]. This information could be used to facilitate quantitative estimation and bioassay-guided separation of pharmacologically active compounds from the plant. The preliminary phytochemical screening of the two solvent extracts from E. schimperi revealed the presence of several secondary metabolites such as saponins, terpenoids, tannins, steroids, polyphenol and flavonoids in moderate to high yield. As indicated in Table 1 below, significant amount of polyphenols, tannins and saponins were observed in methanol leaf extracts compared to chloroform extract, which was detected from the formation of strongly colored solutions.

\section{Determination of total phenolic content}

The total polyphenol content of the leaf extracts was reported in terms of milligram gallic acid equivalent (mg GAE). As follows from Table 2 shown below, gallic acid standard solutions ranging from 50 to $125 \mu \mathrm{g} / \mathrm{mL}$ were used to construct a calibration curve for the determination of the total phenolic content of each sample. It is apparent from Fig. 1 that a straight line with an equation $y=0.00264 x+0.0699$ and a linear regression coefficient $\left(R^{2}\right)$ of 0.997 was obtained.

As depicted in Table 2, high total phenolic content was observed from E. schimperi leaf extracts; namely, methanol extract exhibited the highest level of phenolic content $(748.78 \pm 3.11) \mathrm{mgGAE} / 100 \mathrm{~g}$ dry extract while chloroform extracts exhibited the least $(40.45 \pm 0.66)$ mgGAE/100 g dry extract. This finding, while preliminary, suggests that extraction of phenolic compounds from this plant is influenced by the polarity of the solvent. Several of the recent literature has reported that aqueous mixture of acetone, methanol and ethanol could be better choice for extraction of low- and high-molecular weight phenolic compounds [6]. In this study, extraction of the phenolic compounds using aqueous mixture of methanol (90\% methanol in water) was done but it was noticed that a gummy-type extract resulted and it was not possible to completely redissolve the extract using methanol for further studies. This indicates that in the presence of water as an extracting solvent, the crude extract undergoes in situ polymerization. So this result shows that aqueous solvents are not good solvents particularly for the extraction of E. schimperi leaves.
Table 3 Absorbance of different solvent extract of Euclea schimperi leaves at different concentration for ferric reducing power measurement at $700 \mathrm{~nm}$

\begin{tabular}{lll}
\hline Concentration $(\mathbf{v} / \mathbf{v})$ & \multicolumn{2}{l}{$\begin{array}{l}\text { Absorbance at } 700 \mathrm{~nm} \text { of the reduced } \\
\text { FRAP product for different extracts }\end{array}$} \\
\cline { 2 - 3 } & Methanol & Chloroform \\
\hline $10 \%$ & $0.790 \pm 0.001^{\mathrm{a}}$ & $0.369 \pm 0.003^{\mathrm{b}}$ \\
$20 \%$ & $0.832 \pm 0.002^{\mathrm{a}}$ & $0.505 \pm 0.002^{\mathrm{a}}$ \\
$30 \%$ & $0.872 \pm 0.004^{\mathrm{c}}$ & $0.599 \pm 0.003^{\mathrm{b}}$ \\
$40 \%$ & $0.896 \pm 0.002^{\mathrm{b}}$ & $0.685 \pm 0.001^{\mathrm{a}}$ \\
\hline
\end{tabular}

Values in the same column that are followed by a different letters (a-e) are significantly different $p<0.05$ by Tukey's HSD multiple comparison test

\section{Determination of total flavonoid content}

Calibration curve was constructed to determine the total flavonoid content of E. schimperi leaf extracts. As summarized in Table 2, total flavonoid (TF) contents in the extracts are expressed as mg quercetin equivalent per $100 \mathrm{~g}$ of dry extract (QE/100 g of dried extract). Different concentrations of quercetin $(2,4,6$ and $8 \mu \mathrm{g} /$ $\mathrm{mL}$ ) were used to construct the calibration curve $\left(y=0.0154 x+0.128, R^{2}=0.999\right)$. In fact, the total flavonoid content was very small compared to the total phenolics content of leaf extracts of E. schimperi. On the other hand, the TFC in methanol extract $(3.306 \pm 0.142)$ was relatively higher than that of chloroform extract $(0.334 \pm 0.002)$.

\section{Antioxidant potential determination of extracts of $E$. schimperi leaves \\ Ferric reducing power (FRAP) assay}

The reducing power of the extracts from E. schimperi leaves, which may serve as a significant reflection of the antioxidant activity was evaluated using potassium ferricyanide reduction method. The antioxidant capacity of the E. schimperi leaf extracts with two solvents was evaluated in terms of ascorbic acid equivalent (mg AAE per g dry weight of sample) and this is tabulated in Table 2. For the antioxidant activity determination, aqueous solutions of ascorbic acid standard at different concentrations $(0.2,0.4,0.6,0.8 \mathrm{mg} / \mathrm{mL})$ were used to construct the calibration curve and a straight line with an equation $y=0.3525 x+0.491$ and a linear regression coefficient $\left(R^{2}\right)$ of 0.997 was obtained.

The reducing power of the extracts as a function of different concentrations of extracts is summarized in Table 3 and illustrated in Fig. 1. The graph and the 


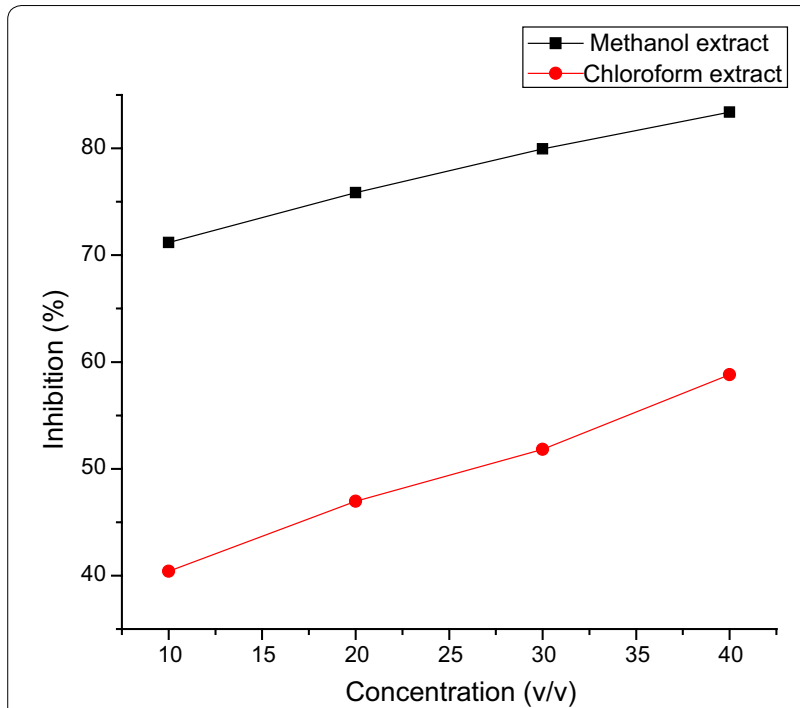

Fig. 2 DPPH radical scavenging activity of Euclea schimperi leaf extracts at different concentration. The methanol and chloroform extracts from Euclea schimperi leaves with different concentrations $(40,30,20,10 \% \mathrm{v} / \mathrm{v})$ of $5.0 \mathrm{mg} / \mathrm{mL}$ stock solutions were prepared. The percent radical scavenging activities of the methanol and chloroform extracts expressed as ascorbic acid equivalents were 19.71 and $2.717 \mathrm{mg} \mathrm{AAE} / 100 \mathrm{~g}$, respectively

analyzed data confirmed that all the extracts exhibited some degree of reducing power. It is apparent from the table that the reducing power increases with increasing concentration. The antioxidant capacity of methanol extract was significantly higher than that of the chloroform extract. This indicates that polar compounds are more responsible for antioxidant activities and a positive correlation was found between TPC and antioxidant activity.

In this assay, the yellow color of the test solution changes to various shades of green when extracts were added which indicates the reducing power of each extracts. The presence of antioxidant causes the conversion of the $\mathrm{Fe}^{3+} /$ ferricyanide complex to the ferrous $/ \mathrm{Fe}^{2+}$ form. Substances which have reduction potential react with potassium ferricyanide $\left(\mathrm{Fe}^{3+}\right)$ to form potassium ferrocyanide $\left(\mathrm{Fe}^{2+}\right)$, then reacts with ferric chloride to form ferrous complex that has an absorption maximum at $700 \mathrm{~nm}$.

\section{DPPH radical scavenging activity determination}

The DPPH radical scavenging activities of the leaf extracts from $E$. schimperi were estimated by comparing the percentage scavenging activity of the DPPH with a standard, ascorbic acid (Table 2). Figure 2 exemplifies the steady increase in scavenging activity of the methanol and chloroform extracts up to $40 \% \mathrm{v} / \mathrm{v}$ of the $5 \mathrm{mg} / \mathrm{mL}$ stock solution of extracts. The methanol and chloroform extracts

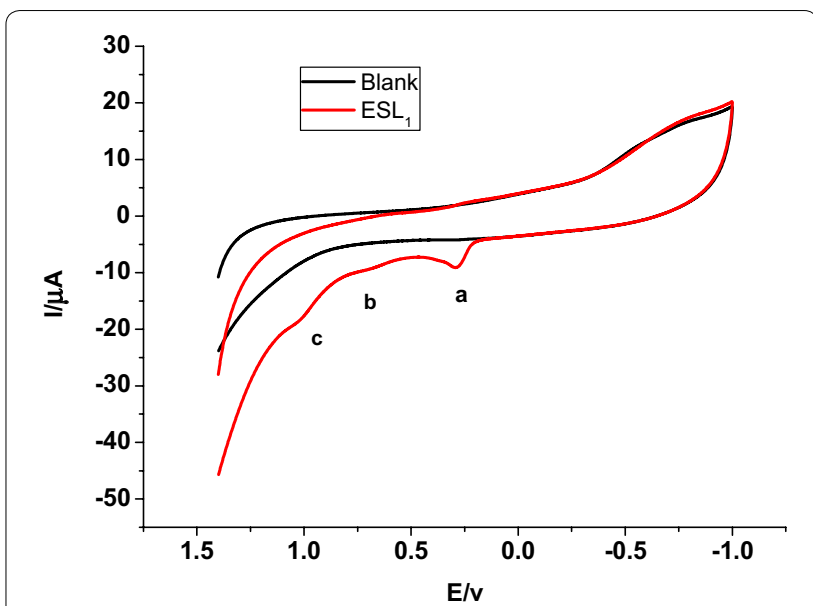

Fig. 3 Cyclic voltammetry analysis of methanol extract of Euclea schimperi leaves. Cyclic voltammogram of each sample was obtained by scanning the potential from -1000 to $1400 \mathrm{mV}$ at a scan rate of $100 \mathrm{~m} \mathrm{Vs}^{-1}$. Acetate buffer was used as a blank. Both CV and SWV gave three different peaks and the only different SWV can scatter the peaks clearly

from E. schimperi were able to scavenge the DPPH radical with percentage scavenging activity of 85.4 and $58.5 \%$ at the highest concentration, respectively. In other words, the percent radical scavenging activities of the methanol and chloroform extracts expressed as ascorbic acid equivalents were 19.71 and $2.717 \mathrm{mg}$ AAE/100 g, respectively. A comparison of the results with the standard reveals that the DPPH radical scavenging capacity of the two

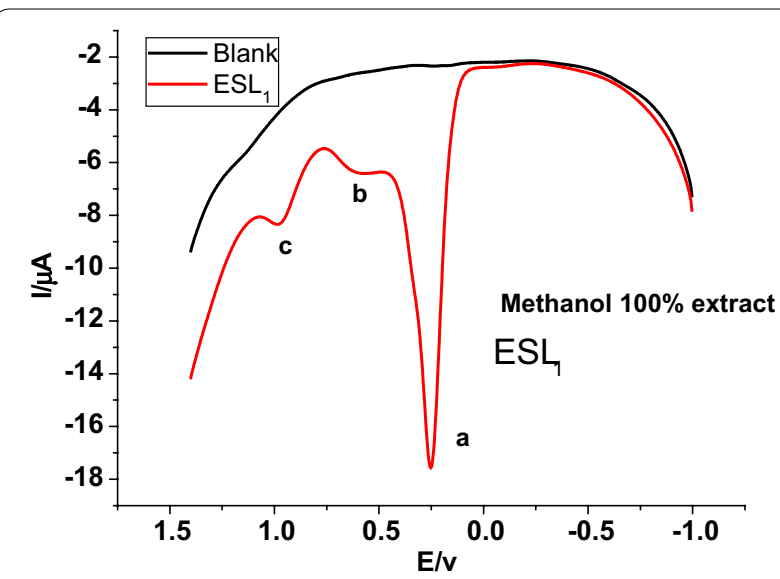

Fig. 4 Square-wave voltammetry analysis of methanol extract of Euclea schimperi leaves. Cyclic voltammetric measurements were performed in model 700 E series electrochemical analyzer connected to a desktop computer. $I_{\text {pa }}(\mu \mathrm{A})=$ electric current in $\mu \mathrm{A}$ of peak ' $a$ ' and $E_{\mathrm{Pa}}(\mathrm{mV})=$ oxidation potential in $\mathrm{mV}$ of peak'a'. Euclea schimperi leaves extract can act as antioxidant species because there were no any peaks at the reduction side. All three peaks were obtained at the oxidation side 
Table 4 Peak parameters of methanol extract of Euclea schimperi leaves obtained from voltammetric analysis

\begin{tabular}{lllllll}
\hline Type of extracts & \multicolumn{5}{l}{ Oxidation peak characters } \\
\cline { 2 - 6 } & $\boldsymbol{I}_{\mathbf{p a}}(\boldsymbol{\mu A})$ & $\boldsymbol{E}_{\mathbf{P a}}(\mathrm{mV})$ & $\boldsymbol{I}_{\mathbf{p b}}(\boldsymbol{\mu A})$ & $\boldsymbol{E}_{\mathbf{p b}}(\mathrm{mV})$ & $\boldsymbol{I}_{\mathbf{p c}}(\boldsymbol{\mu A})$ & $\boldsymbol{E}_{\mathbf{p c}}(\mathbf{m V})$ \\
\hline Methanol & -17.59 & 248.35 & -6.41 & 622.25 & -8.37 & 989.02 \\
\hline
\end{tabular}

$I_{\mathrm{pa}}(\mu \mathrm{A})$, electric current in $\mu \mathrm{A}$ of peak 'a'; $I_{\mathrm{pb}}(\mu \mathrm{A})$, electric current in $\mu \mathrm{A}$ of peak ' $b^{\prime}$; $I_{\mathrm{pc}}(\mu \mathrm{A})$ electric current in $\mu \mathrm{A}$ of peak ' $\mathrm{c}^{\prime}$; $E_{\mathrm{pa}}(\mathrm{mV})$ oxidation potential in $\mathrm{mV}$ of peak 'a'; $E_{\mathrm{pb}}(\mathrm{mV})$, oxidation potential in $\mathrm{mV}$ of peak ' $\mathrm{b}^{\prime} ; E_{\mathrm{pc}}(\mathrm{mV})$, oxidation potential in $\mathrm{mV}$ of peak 'c'

extracts was weaker than ascorbic acid $(89.95 \pm 0.116 \%$ at the concentration of $125 \mu \mathrm{g} / \mathrm{mL}$ ). Another point to consider is methanol extract again retained its superiority in the antioxidant activity. This pattern of DPPH inhibition is commonly observed with plant extracts [18].

\section{Voltammetric analysis, CV}

The voltammetric method can be used for the determination of the antioxidant capability in the same manner as the DPPH radical scavenging because of the correlation found between oxidation potentials and antioxidant power. CV method is frequently preferred for various types of physicochemical analysis in redox system due to its high sensitivity, rapidity, simplicity, the possibility of performing analysis in colored or turbid solutions [24]. It can provide information about the number of redox states as well as qualitative information about the stability of these oxidation states and the electron transfer kinetics [25-27].

Square-wave voltammetry (SWV) is another superior electrochemical technique for both mechanistic and electrokinetic studies of various electrode processes. SWV has several advantages. Among these are its excellent sensitivity, the rejection of background currents and its speed. The current produced is proportional to the combined concentration of the antioxidants [28, 29].

The antioxidant activity of the samples is determined by the ease of phenolic compound to be oxidized. It can
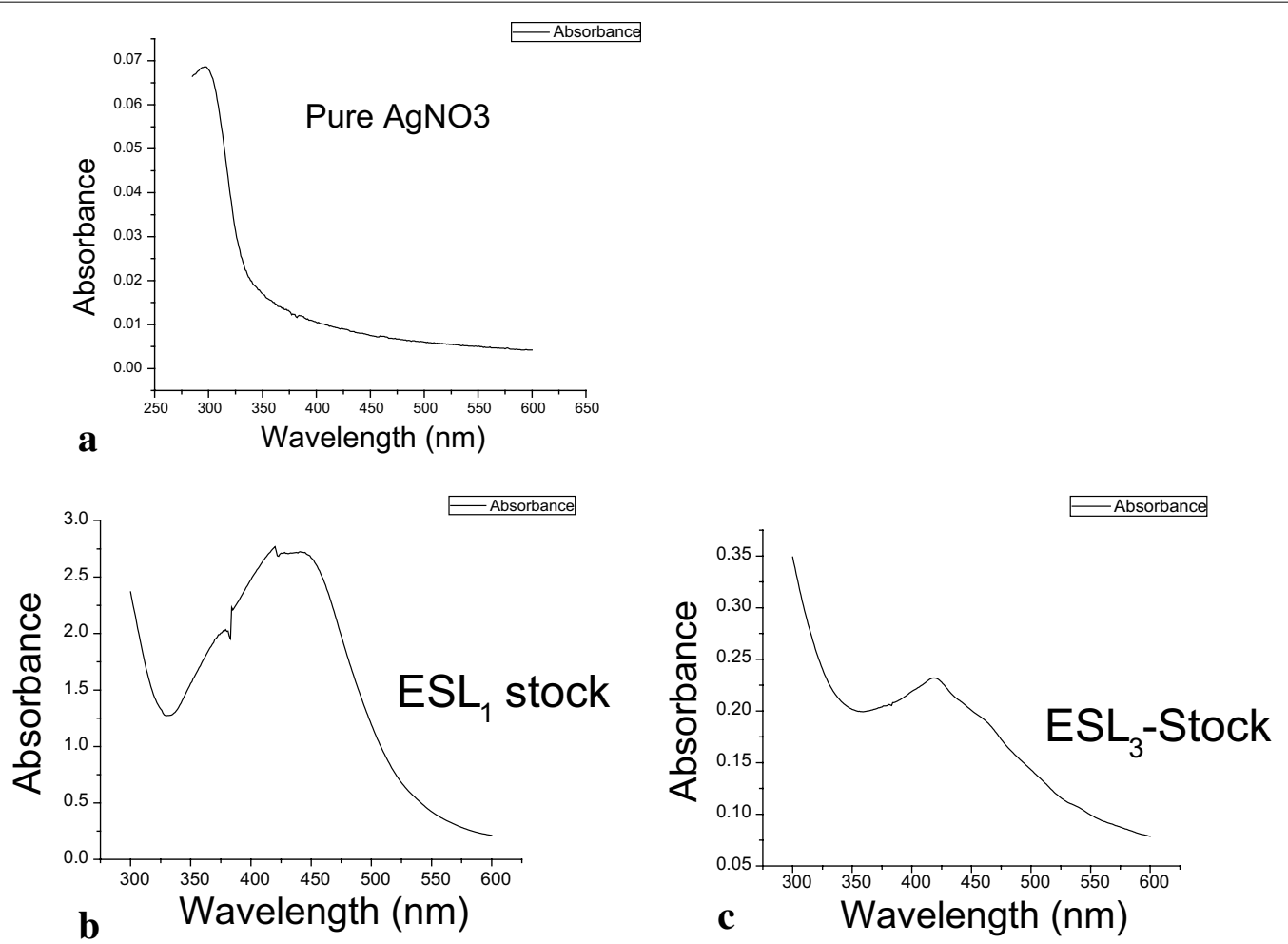

Fig. 5 UV-Vis absorbance of pure silver nitrate solution: a methanol extract $\mathbf{b}$ and chloroform extract $\mathbf{c}$ of Euclea schimperi leaves. The absorbance of the mixture was scanned between 300 and $600 \mathrm{~nm}$ using UV-Vis spectrometer after 2.0, 6.0, 9.0 and $24.0 \mathrm{~h}$ of the reaction begins. When it is stock, the absorption peak of methanol extract gave two non-smooth or trucks. From the UV-Vis absorbance of methanol and chloroform extracts, it was observed that the reduction of silver ions with chloroform extract was extremely smaller than methanol extracts 

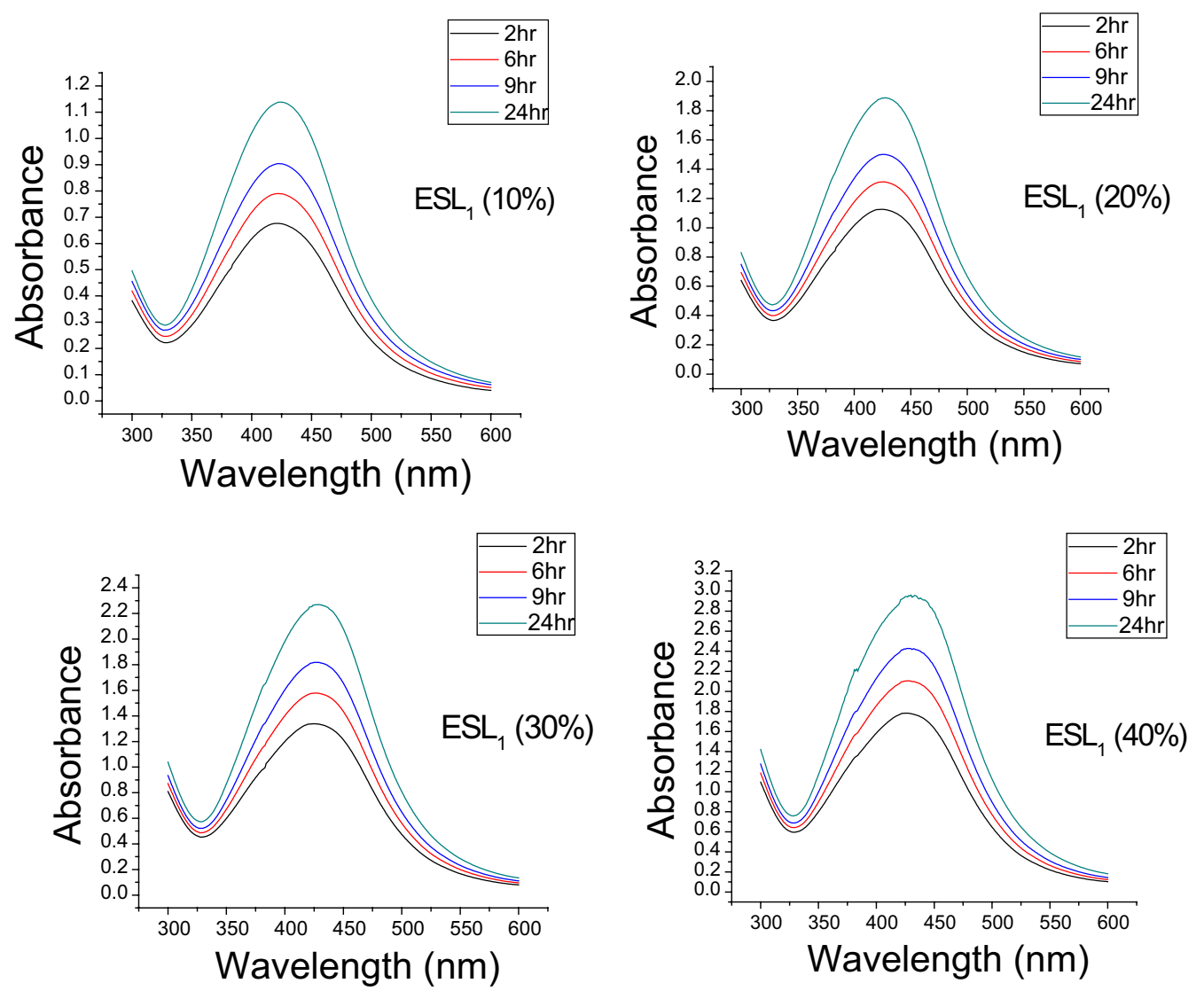

Fig. 6 UV-Vis absorbance of methanol extract of Euclea schimperi leaves of different concentrations (10,20,30 and 40\% v/v) of $5 \mathrm{mg} / \mathrm{mL}$ stock solution separately at different time. As the concentration of the extract increases the absorbance of the mixture also increases

be described as easily oxidizable if its positive oxidation potential is as small as possible (Figs. 3 and 4). Both CV and SWV gave three different peaks; the only different was SWV that can scatter the peaks clearly.

As illustrated in Figs. 3 and 4 above, the voltammetric analysis of E. schimperi leaves extract with methanol solvent gives three different sharp peaks at the oxidation side. This indicates that the extract contains three reductant or antioxidant species that can be either three different group of reductant or a reductant that can be reduced to another substance in step-wise process. Out of these three different peaks, one was very long and sharp indicating that this represents the major component of the three antioxidant components.

As a result, E. schimperi leaves extract can act as antioxidant species because there were no any peaks at the reduction side (all three peaks were obtained at the oxidation side). The peak parameters obtained from the cyclic voltammograms of each sample are tabulated in Table 4.

\section{Synthesis of silver nanoparticles}

On account of noble metal nanoparticles are widely applied to areas of human health, there is a growing interest to develop environmentally friendly processes for nanoparticles synthesis [30]. Biological methods of synthesis have paved way for the "greener synthesis" of nanoparticles and these have proven to be better methods due to slower kinetics, offer better manipulation and control over crystal growth and their stabilization [31,32].

Phytochemicals are involved directly in the reduction of the ions and formation of silver nanoparticles using biological methods [30, 33]. E. schimperi leaf extracts contain a variety of phytochemicals such as polyphenols, flavonoids and terpenoids which help in the reduction of metal ion to form nanoparticles. Preliminary identification of nanoparticle formation was carried out by observing the color change of the reaction mixture. It was observed that when $\mathrm{AgNO}_{3}$ solution was mixed with the plant extracts, brown coloration was observed due to the formation of silver nanoparticles. This is a clear indication of the formation of silver nanoparticles [34]. 

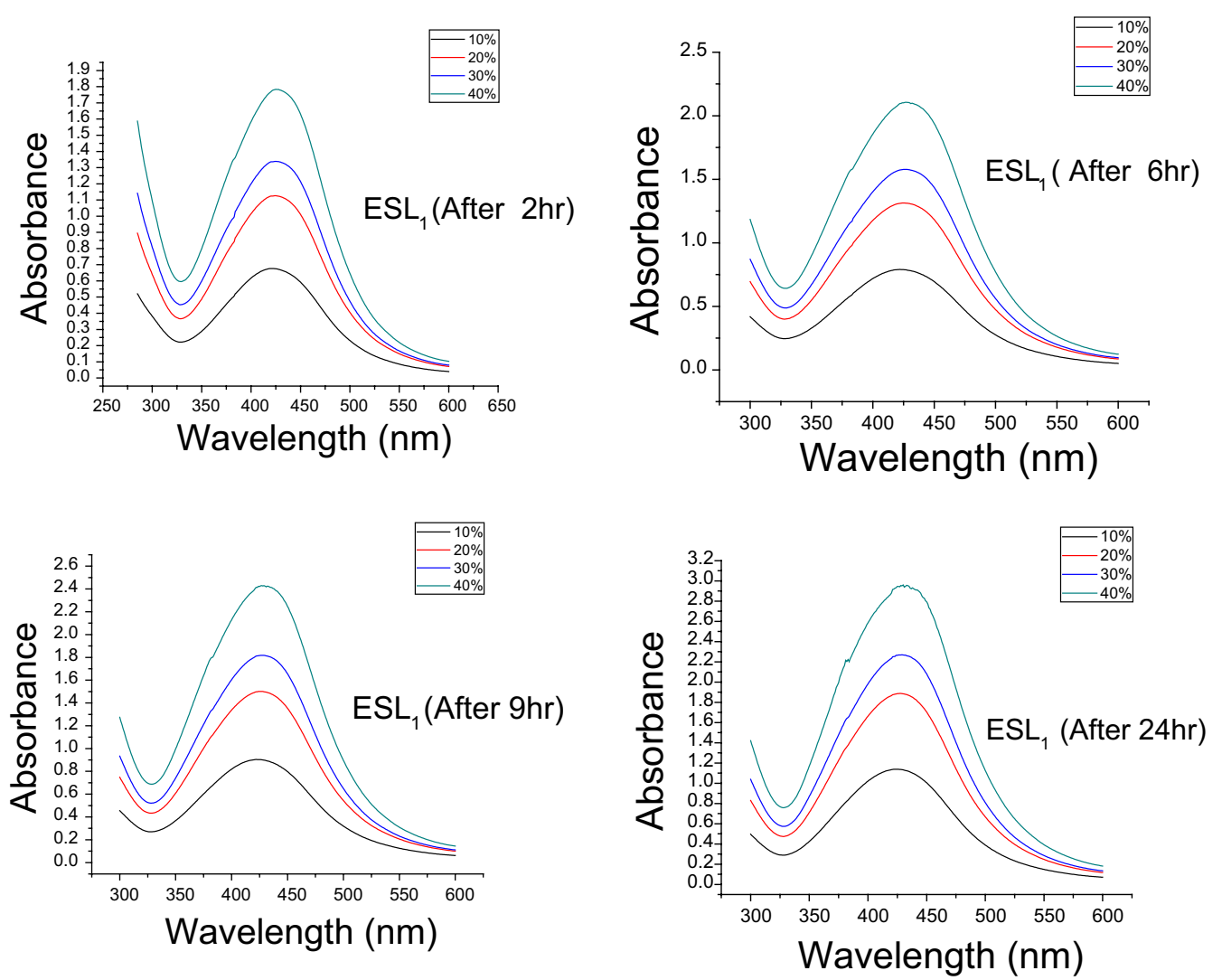

Fig. 7 UV-Vis absorbance of different concentration of methanol extract of Euclea schimperi leaves after different reaction time. As the contact or reaction time increases, the formation of silver nanoparticles increases which leads to an increases in absorbance of the mixture. The peak observed in the methanol extract is clearly visible around $428 \mathrm{~nm}$ which indicates the reduction of silver ions

Table 5 Comparison of inhibition zone in $\mathrm{mm}$ among different crude extracts of Euclea schimperi leaves and positive controls against standard drug resistance Gram-positive and Gram-negative bacteria

\begin{tabular}{|c|c|c|c|c|}
\hline \multirow{3}{*}{$\begin{array}{l}\text { Types of extracts or positive } \\
\text { control }\end{array}$} & \multicolumn{4}{|c|}{ Types of bacteria strain } \\
\hline & \multicolumn{2}{|l|}{ Gram positive } & \multicolumn{2}{|l|}{ Gram negative } \\
\hline & S. aurous & S. pneumoniae & P. aeruginosa & K. pneumoniae \\
\hline Methanol extract & $20.67 \pm 1.53^{\mathrm{a}}$ & $0.00^{a}$ & $17.00 \pm 1.00^{\mathrm{a}}$ & $0.00^{\mathrm{a}}$ \\
\hline Chloroform & $15.00 \pm 1.00^{b}$ & $0.00^{a}$ & $14.33 \pm 0.58^{b}$ & $0.00^{a}$ \\
\hline Erythromycin & $23.00 \pm 0.05$ & $22.00 \pm 0.20$ & - & - \\
\hline Chloramphenicol & $24.20 \pm 0.30$ & $23.00 \pm 0.07$ & - & - \\
\hline Gentamycin & - & - & $14.00 \pm 0.05$ & $18.00 \pm 0.35$ \\
\hline Ciprofloxacin & - & - & $30.30 \pm 1.23$ & $20.30 \pm 0.89$ \\
\hline
\end{tabular}

S. pneumoniae, Streptococcus pneumoniae; S. aureus, Staphylococcus aureus; P. aeruginosa, Pseudomonas aeuroginosa; K. pneumonia, Klebsiella pneumonia Values in the same column that are followed by a different letters $(a, b)$ are significantly different $p<0.05$ by paired $t$ test

Therefore, the present investigation demonstrates the formation of silver nanoparticles by the reduction of aqueous silver ions from E. schimperi leaf extracts using different solvents. The properties of the nanoparticle and its reduction time depend on various characteristics of plant extract, namely concentration of the metal salt and the extracts, contact time and reaction temperature. Nevertheless, this study considered two major factors, contact time and concentration of the plant extracts. As a result, the formation of silver nanoparticles by reduction 


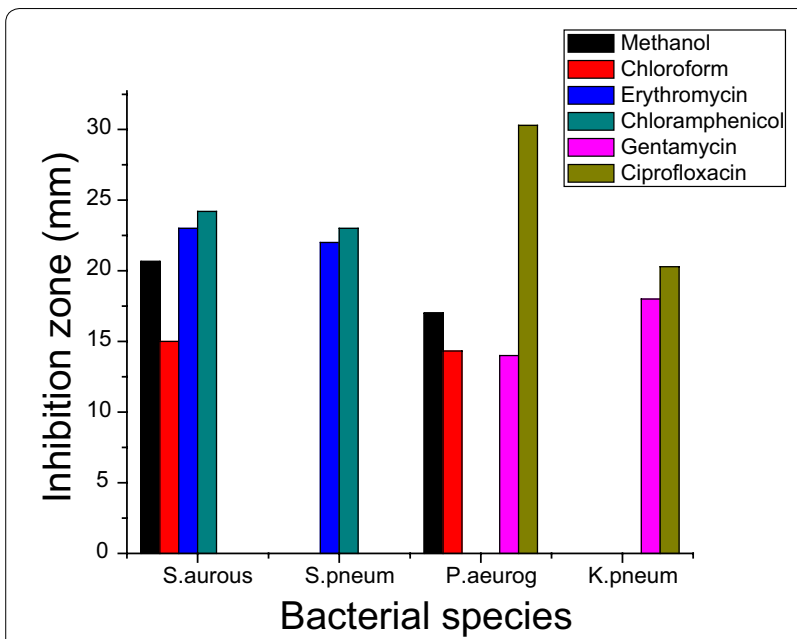

Fig. 8 Comparison of inhibition zone among crude extracts of Euclea schimperi leaves using different solvent (methanol and chloroform) against standard Gram-positive and Gram-negative bacteria. Standardized inoculums of the test organisms were inoculated into series of sterile tubes of $2 \mathrm{~mL}$ nutrient broth containing 500, 250, 125, 62.5 and $31.25 \mathrm{mg} / \mathrm{mL}$ of each extracts and incubated at $37^{\circ} \mathrm{C}$ for $24 \mathrm{~h}$. The methanol extract showed maximum antibacterial activity against S. aureus and P. aeuroginosa with diameter of $20.67 \pm 1.53$ and $17 \pm 1 \mathrm{~mm}$ at concentrations of $500 \mathrm{mg} / \mathrm{mL}$, respectively. Chloroform extract also exhibited antibacterial activity against $S$. aures and $P$. aeuroginosa with diameter of $15 \pm 1$ and $14.33 \pm 0.58 \mathrm{~mm}$ at concentrations of $500 \mathrm{mg} / \mathrm{mL}$, respectively

of silver ions was measured with different concentrations $(10,20,30,40 \% \mathrm{v} / \mathrm{v})$ of $E$. schimperi leaf extracts at different reaction time (2, 6, 9 and $24 \mathrm{~h})$.

When it is stock, the absorption peak of methanol extract gave two non-smooth or trucks. This may be due to higher deposition of silver nanoparticles. From the UV-Vis absorbance of methanol and chloroform extracts of E. schimperi leaves, it was observed that the reduction of silver ions with chloroform extract was extremely smaller than methanol extracts (Fig. 5).

Initially, the reacting mixture was a slightly yellowish liquid; as the reaction proceeded, the solutions became dark brown. Different concentrations (10, 20, 30 and
$40 \%)$ of methanol extract of E. schimperi leaves result in the formation of different absorption peaks. As the concentration of the extract increases the absorbance of the mixture also increases (Fig. 6). The visual inspection of the color change of the mixture from yellow to intense brown was demonstrated with increase in concentration of the leave extracts. This also ascertains the dependence of the formation of silver nanoparticles on the concentration of the extracts. The absorbance of silver nanoparticles in the presence of different concentrations of the extract at different time can be found in Fig. 6.

Another point to consider is as the contact or reaction time increases, the formation of silver nanoparticles increases which leads to an increases in absorbance of the mixture. This result is shown in Fig. 7.

Additionally, as both the concentration of the plant extract and the reaction time increase, non-smooth part of the peak around the same wave length region was increased. This is due to the increase in the concentration of silver nanoparticles formed in the reaction.

As can be seen from the Figs. 6 and 7 above, the peak observed in the methanol extract of E. schimperi leaves is clearly visible around $428 \mathrm{~nm}$ which indicate the reduction of silver ions.

\section{Determination of antibacterial activity of $E$. schimperi leaf extracts Agar disk diffusion method}

Methanol extract of E. schimperi leaves exhibited prominent antibacterial activity against both one Grampositive and one Gram-negative bacterial species. The chloroform extract of the plant sample also exhibited inhibition zone on some bacterial species but it was not as strong as methanol extract. The inhibition zones obtained by each solvent extract of leaves of E. schimperi and the control against each tested microorganism are summarized in Table 5. The results were expressed as mean \pm standard deviation of triplicate measurements.

As shown in Fig. 8 and Table 5, zone of inhibition of the tested extract against different bacterial species of the methanol extract showed maximum antibacterial activity against $S$. aureus and $P$. aeuroginosa with diameter of

Table 6 MIC determination of Euclea schimperi leave extracts against Gram-positive and Gram-negative bacteria

\begin{tabular}{|c|c|c|c|c|c|c|c|}
\hline \multirow[t]{2}{*}{ Bacterial species } & \multirow[t]{2}{*}{ Types of extract } & \multicolumn{6}{|c|}{ Concentration $(\mathrm{mg} / \mathrm{mL})$} \\
\hline & & 500.0 & 250.0 & 125.0 & 62.5 & 31.25 & MIC \\
\hline \multirow[t]{2}{*}{ S. aureus } & Methanol & - & - & - & - & + & 62.5 \\
\hline & Chloroform & - & - & - & + & + & 125 \\
\hline \multirow[t]{2}{*}{ P. aeuroginosa } & Methanol & - & - & - & - & + & 62.5 \\
\hline & Chloroform & - & - & - & + & + & 125 \\
\hline
\end{tabular}

- , inhibition of bacterial growth; + , turbidity (slight bacterial growth) 
$20.67 \pm 1.53$ and $17 \pm 1 \mathrm{~mm}$ at concentrations of $500 \mathrm{mg} /$ $\mathrm{mL}$, respectively. Chloroform extract also exhibited antibacterial activity against $S$. aures and $P$. aeuroginosa with diameter of $15 \pm 1$ and $14.33 \pm 0.58 \mathrm{~mm}$ at concentrations of $500 \mathrm{mg} / \mathrm{mL}$, respectively. The antimicrobial activity of methanol leaf extracts of $E$. schimperi was stronger than chloroform extracts towards the tested pathogens. This substantiates that more polar bioactive compounds are extracted more by methanol than chloroform. In other words, alcoholic extracts of tested plants provided better antibacterial effect than other solvents [35]. Both methanol and chloroform extracts showed no activity against $S$. pneumoniae and K. pneumoniae (multidrug resistance).

The presence of zone of inhibition around the well was considered positive. The extracts were found to cause marked inhibition of bacteria in a dose-dependent manner. Among bacteria, Gram-positive bacteria have shown higher sensitivity to the extracts compared to Gramnegative bacteria. The inhibition caused by methanol extract was lesser than that of standard antibiotic since the standard antibiotic are found in pure form [36].

Alkaloids, tannins, saponins, glycosides and steroid derived from plants have been shown to have antimicrobial effect and pharmacological activities [37, 38]. Flavonoids, phenols, saponins, steroids, tannins, and terpenes detected from the extracts are responsible to observed antibacterial action of E. schimperi leaf extracts. In summary, this antibacterial action may serve as justification to the traditional use of the E. schimperi plant against various human disorders.

\section{Determination of minimum inhibitory concentration (MIC)}

The MIC was taken as the lowest concentration that prevented bacterial growth and it was determined using a broth dilution test.

As shown in Table 6, the MIC values were evaluated relatively at higher concentrations of the methanol $(62.5 \mathrm{mg} / \mathrm{mL})$ and chloroform $(125 \mathrm{mg} / \mathrm{mL})$ extracts. Correspondingly, methanol extract afforded notable MIC value at $62.5 \mathrm{mg} / \mathrm{mL}$ against both $S$. aureus and $P$. aeuroginosa. An implication of these findings is that E. schimperi leaf extracts can inhibit some of the bacterial species at relatively high concentration.

\section{Conclusion}

The outcome of our investigation clearly indicated that E. schimperi leaf extracts were found to contain high amount of total phenolic and small amount of flavonoids content. Likewise, the extracts revealed significant antioxidant activities against various tests; FRAP, DPPH, voltammetric analysis and silver nanoparticle reduction. Based on the results, the methanol extract showed higher reducing capacity, DPPH radical scavenging activity, anodic peak current and smaller positive oxidation potential than the chloroform extract. The methanol extract can also reduce silver ion and able to form significant amount of silver nanoparticles. Last, the result can also prove the effectiveness of E. schimperi leaf extracts for antimicrobial activity.

In general, the methanol extracts demonstrated superior antioxidant and antimicrobial effects than chloroform extracts, which is related to the quantity of phytochemicals present in the crude extracts. To this end, the findings are quite convincing to scientifically confirm the traditional use of this plant for medicinal purpose by the population.

\section{Authors' contributions \\ AM and MA conceived and designed the experiments: AM analyzed data and wrote the paper; BK performed the experiments. All authors participated in the revisions of the manuscript. All authors read and approved the final manuscript.}

\section{Acknowledgements \\ The authors are thankful to Bahir Dar University for the provision of lab facility and Dr. Maereg Amare for obtaining voltammetric data.}

\section{Competing interests \\ The authors declare that they have no competing interests.}

\section{Availability of data and materials}

Aherbarium voucher (Banchalem-001) was identified by Dr. Ali Seid and deposited in the mini-herbarium of a Bahir Dar University, (Bahir Dar, Ethiopia). All data generated or analyzed during this study are included in this published article.

\section{Consent for publication \\ Not applicable.}

Ethics approval and consent to participate

Not applicable.

Funding

Not applicable.

\section{Publisher's Note}

Springer Nature remains neutral with regard to jurisdictional claims in published maps and institutional affiliations.

Received: 5 June 2018 Accepted: 11 July 2018

Published online: 08 August 2018

\section{References}

1. Ignacimuthu S, Ayyanar M, Sankara Sivaraman K. Ethnobotanical investigations among tribes in Madurai district of Tamil Nadu (India). J Ethnobiol Ethnomed. 2006;11(25):1-7.

2. Hammer KA, Carson CF, Riley TV. Antimicrobial activity of essential oils and other plant extracts. J Appl Microbiol. 1999;86:985-90.

3. Giday M, Asfaw Z, Elmqvist T, Woldu Z. An ethnobotanical study of medicinal plants used by the Zay people in Ethiopia. J Ethnopharmacol. 2003:85:43-52.

4. Sukhdev S, Suman PSK, Gennaro L, Dev DR. Extraction technologies for medicinal and aromatic plants. Trieste: International Centre for Science and High Technology; 2008.

5. Hasler CM, Blumberg JB. Phytochemicals: biochemistry and physiology. Introduction. J nutr. 1999;129(3):756S-7S. 
6. Evans WC. General methods associated with the phytochemical investigation of herbal products. Trease and Evans pharmacognosy. 15th ed. Philadelphia: Saunders/Elsevier; 2008. p. 137-48.

7. Hamilton AC. Medicinal plants, conservation and livelihoods. Biodivers Conserv. 2004;13:1477-517.

8. Wang H, Liu YM, Qi ZM, Wang SY, Liu SX, Li X, Wang HJ, Xia XC. An overview on natural polysaccharides with antioxidant properties. Curr Med Chem. 2013;20:2899-913.

9. Liu Y, Sun Y, Huang G. Preparation and antioxidant activities of important traditional plant polysaccharides. Int J Biol Macromol. 2018;111:780-6.

10. Huang G, Mei X, Hu J. The antioxidant activities of natural polysaccharides. Curr Drug Targets. 2017;18(11):1296-300.

11. Nwachukwu CU, Umeh CN, Kalu IG, Okere S, Nwoko M. Identification and traditional uses of some common medicinal plants in Ezinihitte Mbaise LGA, of Imo State, Nigeria. Rep Opin. 2010;2:1-10,

12. De Moura KC, Emery FS, Neves-Pinto C, Pinto MD, Dantas AP, Salomão K, Castro SL, Pinto AV. Trypanocidal activity of isolated naphthoquinones from Tabebuia and some heterocyclic derivatives: a review from an interdisciplinary study. J Br Chem Soc. 2001;12:325-38.

13. Gebre-Mariam T, Neubert R, Schmidt PC, Wutzler P, Schmidtke M. Antiviral activities of some Ethiopian medicinal plants used for the treatment of dermatological disorders. J Ethnopharmacol. 2006;104:182-7.

14. Mikayel G, Margarit P, Armen T. Antimicrobial activity of some plant materials used in Armenian traditional medicine. BMC Complement Altern Med. 2017;17:50-8

15. Gohari AR, Hajimehdipoor H, Saeidnia S, Ajani Y, Hadjiakhoondi A. Antioxidant activity of some medicinal species using FRAP assay. J Med Plants. 2011;10(37):54-60.

16. Amin I, Norazaidah Y, Hainida KE. Antioxidant activity and phenolic content of raw and blanched Amaranthus species. Food Chem. 2006;94:47-52.

17. Chang CC, Yang MH, Wen HM, Chern JC. Estimation of total flavonoid content in propolis by two complementary colorimetric methods. J Food Drug Anal. 2002;10:178-82.

18. Milan C, Hana C, Petko D, Maria K, Anton S, Antonin L. Different methods for control and comparison of the antioxidant properties of vegetables. Food Control. 2010;21:518-23.

19. Louli V, Ragoussis N, Magoulas K. Recovery of phenolic antioxidants from wine industry by-products. Bioresour Technol. 2004;92:201-8.

20. Shankar SS, Rai A, Ahmad A, Sastry M. Rapid synthesis of Au, Ag, and bimetallic Au core-Ag shell nanoparticles using Neem (Azadirachta indica) leaf broth. J Colloid Interface Sci. 2004:275:496-502.

21. Enzo AP. Traditional medicinal plant extracts and natural products with activity against oral bacteria: Potential application in the prevention and treatment of oral diseases. Evid Based Complement Altern Med. 2011:2011:1-15.

22. Akinyemi KO, Oladapo O, Okwara CE, Ibe CC, Fasure KA. Screening of crude extracts of six medicinal plants used in South-West Nigerian unorthodox medicine for anti-methicillin resistant Staphylococcus aureus activity. BMC Complement Altern Med. 2005;5(6):1-7.
23. Tahiya HAA, Amira HSAM, Mohammad AH, Afaf MW, Qasim AR. Comparative study of phytochemical screening, antioxidant and antimicrobial capacities of fresh and dry leaves crude plant extracts of Datura metel L. J King Saud Univ. 2014;26(3):237-43.

24. David IG, Bizgan AM, Popa DE, Buleandra M, Moldovan Z, Badea IA, Tekiner TA, Basaga H, Ciucu AA. Rapid determination of total polyphenolic content in tea samples based on caffeic acid voltammetric behaviour on a disposable graphite electrode. Food Chem. 2015;173:1059-65.

25. Jelen F, Kourilova A, Hason S, Kizek R, Trnkova L. Voltammetric study of adenine complex with copper on mercury electrode. Electroanalysis. 2009;21(3-5):439-44

26. Adam V, Fabrik I, Kizek R, Eckschlager T, Stiborova M, Trnkova L. Vertebrate metallothioneins as target molecules for analytical techniques. TrAC Trends Anal Chem. 2010;29(5):409-18.

27. Hynek D, Krejcova L, Sochor J, Cernei N, Kynicky J, Adam V, Trnkova L, Hubalek J, Vrba R, Kizek R. Study of interactions between cysteine and cadmium (II) ions using automatic pipetting system off-line coupled with electrochemical analyser. Int J Electrochem Sci. 2012;7(3):1802-19.

28. Kilmartin PA, Zou H, Waterhouse AL. Correlation of wine phenolic composition versus cyclic voltammetry response. Am J Enol Vitic. 2002;53(4):294-302

29. Huang T, Gao P, Hageman MJ. Rapid screening of antioxidants in pharmaceutical formulation development using cyclic voltammetry-potential and limitations. Curr Drug Discov Technol. 2004;1 (2):173-9.

30. Song JY, Kim BS. Rapid biological synthesis of silver nanoparticles using plant leaf extracts. Bioprocess Biosyst Eng. 2009;32(1):79-84.

31. Sonvico F, Dubernet C, Colombo P, Couvreur P. Metallic colloid nanotechnology, applications in diagnosis and therapeutics. Curr Pharm Des. 2005:11(16):2091-105.

32. Shipway AN, Katz E, Willner I. Nanoparticle arrays on surfaces for electronic, optical, and sensor applications. Chemphyschem. 2000;1(1):18-52.

33. Bar H, Bhui DK, Sahoo GP, Sarkar P, De SP, Misra A. Green synthesis of silver nanoparticles using latex of Jatropha curcas. Colloids Surf A Physicochem Eng Asp. 2009;339:134-9.

34. Jain D, Daima HK, Kachhwaha S, Kothari SL. Synthesis of plant-mediated silver nanoparticles using papaya fruit extract and evaluation of their anti microbial activities. Dig J Nanomat Biostruct. 2009;4:557-63.

35. Bakht N, Humaira F, Madiha A, Ihsan-ul-Haq. Recent trends and methods in antimicrobial drug discovery from plant sources. Austin J Microbiol. 2015;1(1):1-12.

36. Prescott LM, Harley JP, Klein OA. Microbial nutrition, types of media. New York: McGraw Hill Publishers; 2005. p. 95-105.

37. leven M, Vanden BD, Mertens F, Vlietinck A, Lammens E. Screening of higher plants for biological activities I. Antimicrobial activity. Planta Medica. 1979;36:311-21.

38. Frei B, Heinrich M, Bork PM, Herrmann D, Jaki B, Kato T, Kuhnt M, Schmitt J, Schühly W, Volken C, Sticher O. Multiple screening of medicinal plants from Oaxaca, Mexico: ethnobotany and bioassays as a basis for phytochemical investigation. Phytomedicine. 1998;5:177-86.

\section{Submit your manuscript to a SpringerOpen ${ }^{\circ}$ journal and benefit from:}

- Convenient online submission

- Rigorous peer review

- Open access: articles freely available online

- High visibility within the field

- Retaining the copyright to your article

Submit your next manuscript at $\boldsymbol{\nabla}$ springeropen.com 